\title{
Lesión por estrés de la fisis distal del fémur. Reporte de un caso y revisión del tema
}

\author{
Fiorella Celsi Y.', Gonzalo Corral G. ${ }^{2}$, Carolina Diamante'.
}

1. Médico cirujano. Universidad de Los Andes. Santiago, Chile.

2. Radiólogo. Hospital Exequiel González Cortés. Clínica Dávila. Clínica Las Condes. Santiago, Chile.

\section{Distal physis femur stress injury}

\begin{abstract}
In this case report we present a 14-year-old patient with no previous medical history, who asked for knee pain. He was diagnosed with stress injury of the femur physis. The literature shows that this type of injuries are frequent in young athletes and the mechanism that leads to physeal widening is produced by a repeated trauma that generates mechanical stress and distraction of the growth cartilage. The aim of this case report is to show the relevance of radiology in the early diagnosis of this disease preventing future complications.
\end{abstract}

Keywords: Physeal widening, stress injury, athletes.

Resumen. En este reporte presentamos el caso de un niño de 14 años sin antecedentes mórbidos, que consulta por un cuadro de gonalgia, confirmándose el diagnóstico mediante resonancia magnética (RM) de lesión por estrés de la fisis distal del fémur. La literatura muestra que este tipo de lesiones son frecuentes en pacientes jóvenes deportistas y que el mecanismo que lleva al engrosamiento fisiario se produce por un trauma repetido que genera estrés mecánico y distracción del cartílago de crecimiento. El objetivo de esta publicación es aportar un caso a la literatura y dar a conocer la importancia de la radiología en el diagnóstico precoz de esta enfermedad, para que de esta forma el paciente no presente complicaciones futuras.

Palabras clave: Engrosamiento fisiario, lesión, estrés, deportistas.

Celsi F., et al. Lesiones musculares deportivas: Correlación entre anatomía y estudio por imágenes. Rev Chil Radiol 2018; 24(1): 18-21.

Correspondencia: Gonzalo Corral G. / gonzalocorral@gmail.com

Trabajo enviado el 10 de enero de 2018. Aceptado para publicación el 14 de mayo de 2018.

\section{Introducción}

Paciente de 14 años, sin antecedentes médicos de importancia, cadete de escuela de fútbol. Consulta por gonalgia derecha de un mes de evolución, no invalidante, que se acentúa después de la actividad física. Al examen físico destaca dolor lateral de rodilla derecha.

Se solicita Rx (Figura 1) y RM de rodilla derecha (Figura 2).

\section{Diagnóstico}

Lesión por estrés de la fisis distal del fémur.

\section{Discusión}

El engrosamiento fisiario como manifestación de una lesión por estrés ha sido descrito en pacientes deportistas jóvenes que practican fútbol, béisbol, basquetbol y gimnasia, entre otras actividades, afectando distintas articulaciones
La localización de la lesión varía según el tipo de deporte: la fisis proximal del humero es la más afectada en el béisbol, la muñeca en la gimasia y la fisis distal del fémur tanto en fútbol como en atletismo'.

El cartílago de crecimiento es la zona más débil del esqueleto en desarrollo. Puede dañarse por una actividad intensa repetitiva, alterando incluso el crecimiento si no se corrige la injuria ${ }^{1}$.

El mecanismo lesional que lleva al engrosamiento de la fisis se origina en trauma repetido que genera estrés mecánico y distracción del cartílago de crecimiento, lo que estimula la proliferación e hipertrofia de los condrocitos. Por otra parte, los cambios inflamatorios comprometen la irrigación de la metáfisis, que dificulta la llegada de calcio, fosfato y vitamina $\mathrm{D}$ al hueso en formación. Lo anterior trae como consecuencia una falla en la osificación endocondral, disminución de la osteogénesis y engrosamiento fisiario hacia la metáfisis². 


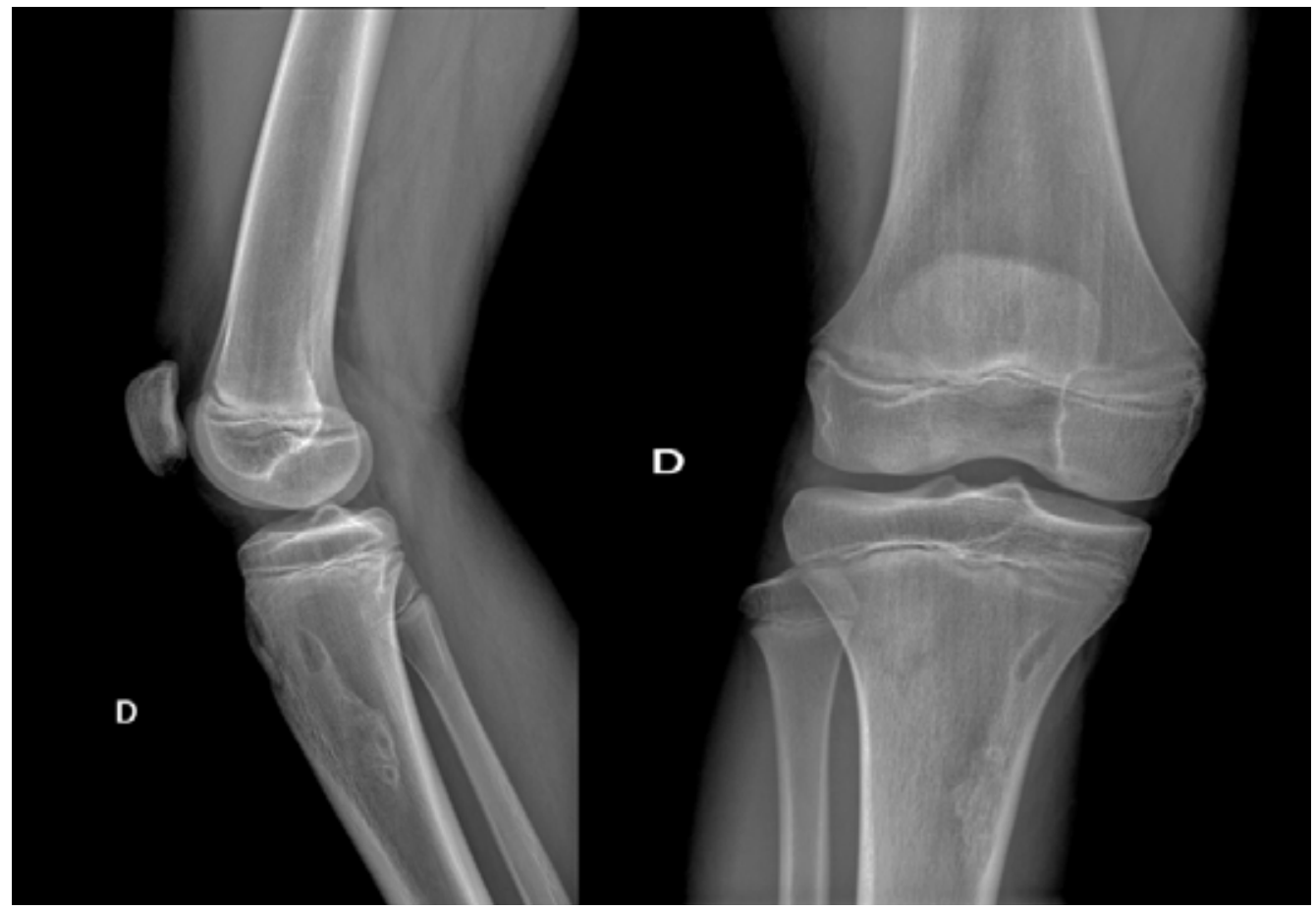

Figura 1. Rx rodilla derecha; Proyección frontal (a) y lateral (b). Se identifica fibroma no osificante en el aspecto anteromedial de la región metafisio-diafisiaria de la tibia proximal, mayormente esclerótico, sin otros hallazgos patológicos.
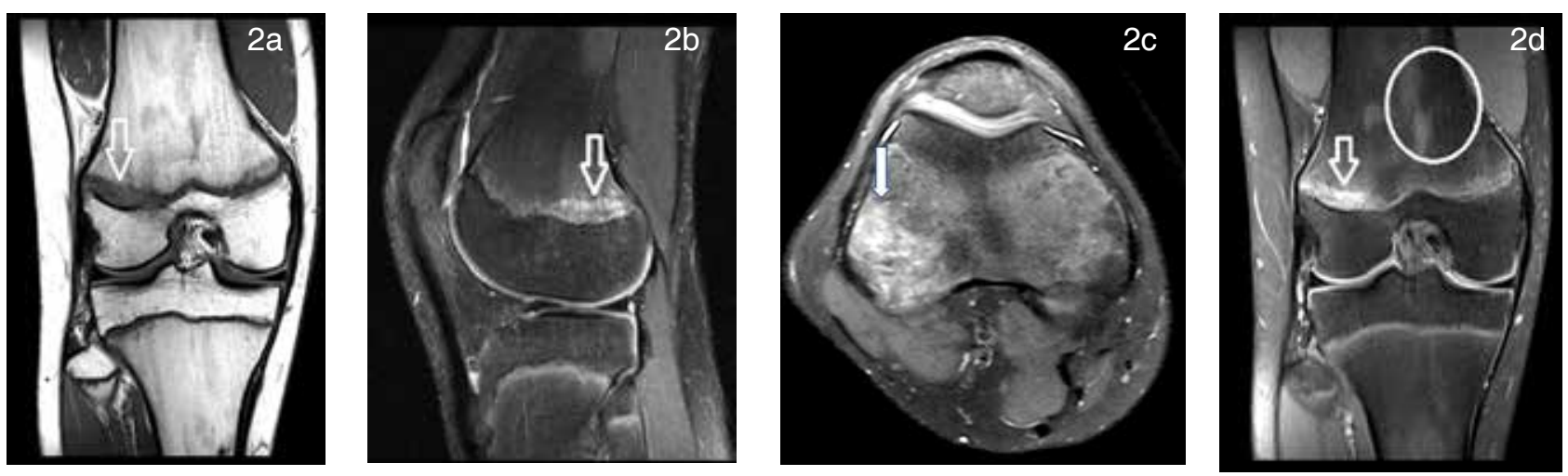

Figura 2 a,b,c,d. RM de rodilla derecha: T1 coronal (a), DP fat- sat sagital (b), axial (c), coronal (d). Se evidencia engrosamiento e irregularidad del aspecto posterolateral de la fisis distal del fémur $(\downarrow)$. La médula ósea muestra señal heterogénea a nivel metafisiario por presencia de médula roja hematopoyética $(O)$, normal para la edad.

La historia clínica característica de este tipo de lesiones corresponde a un adolescente deportista que consulta por dolor crónico localizado en las extremidades, sin antecedente de trauma agudo ${ }^{3}$. El diagnóstico se realiza por clínica e imágenes. En la radiografía $(\mathrm{Rx})$ se puede observar engrosamiento $e$ irregularidad de la fisis involucrada, hallazgos que no eran evidentes en el caso reportado ${ }^{4}$.

La resonancia magnética (RM) se utiliza cuando la $R x$ no es concluyente, en casos que se requiera confirmar el diagnóstico y/o se estime necesario profundizar en el estudio. La RM amplía el diagnóstico diferencial con patología traumática aguda y otros tipos de lesiones por estrés, como fracturas trabeculares 0 apofisitis en zonas de inserción músculotendíneas. Las secuencias de mayor utilidad para evaluar el cartílago hialino, por lo tanto la fisis, son las sensibles al agua (idealmente T2 TSE con saturación espectral de grasa, STIR o DP fat-sat, ampliamente utilizado en estudios de rutina) y también la secuencia eco de gradiente con saturación espectral de grasa potenciada en T1 o T2, que permite delinear adecuadamente la morfología fisiaria y efectuar reconstrucciones 3D para reconocer complicaciones, como por ejemplo barras fisiarias. 


\section{Histológicamente la fisis presenta dos regiones diferentes:}

- La primera, más cercana a la epífisis, es cartilaginosa e incluye las zonas germinal, proliferativa y capa hipertrófica. Esta área se observa hiperintensa en secuencias sensibles al agua, al igual que el cartílago articular, por lo que permite diferenciar los tres tipos de cartílago hialino: articular, epifisisario y fisiario

- La segunda, más cercana a la metáfisis, es la zona de calcificación provisional que contiene una fina matriz altamente calcificada y se representa hipointensa en todas las secuencias. Adyacente a la anterior se puede identificar una tercera capa, la esponjosa primaria, que histológicamente es parte de la metáfisis, pero que imaginológicamente se incluye en el concepto de fisis, otorgando un aspecto "trilaminar". Se caracteriza por ser altamente vascularizada e hiperintensa en secuencias sensibles al agua (Figuras 3 y 4 ).

Cabe destacar que, en secuencias de tiempo de eco corto, como las potenciadas en T1 y DP, se pierde el límite entre el cartílago epifisiario y la fisis, debido a que presentan idéntica intensidad de señal.

Cuando exista una alteración por estrés, la RM nos mostrará pérdida de la morfología normal de la placa de crecimiento asociada a engrosamiento focal o difuso y en las injurias más crónicas puede observarse extensión del cartílago no mineralizado dentro de la metáfisis, en forma en forma de "lengüetas"
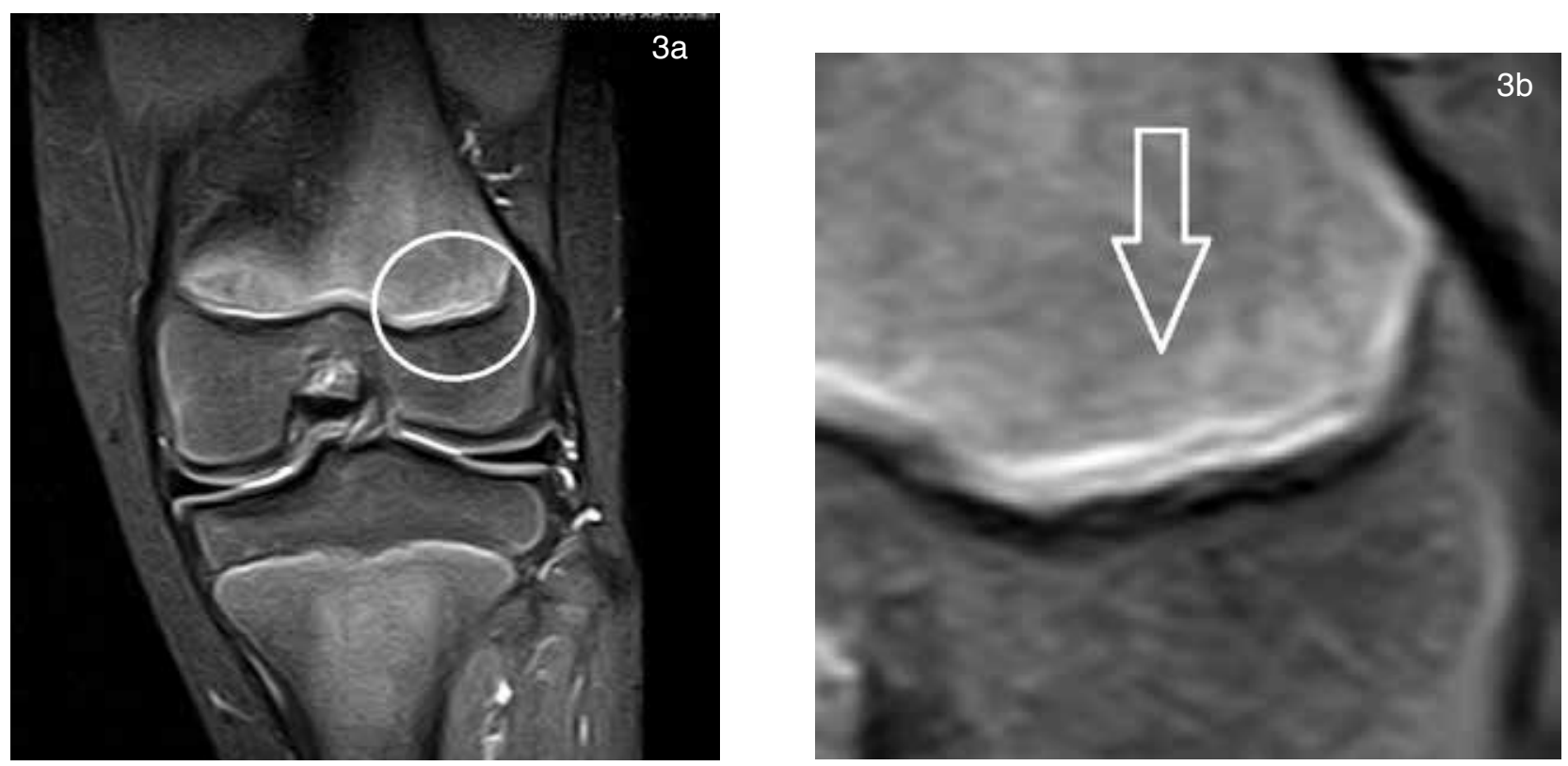

Figura 3. RM normal de paciente de 9 años; secuencia STIR, plano coronal. (a) Cartílago articular hiperintenso (*), epifisiario hipointenso $\left(^{* *}\right.$ y fisiario hiperintenso (\#). (b) Imagen ampliada, muestra el aspecto trilaminar de la fisis.

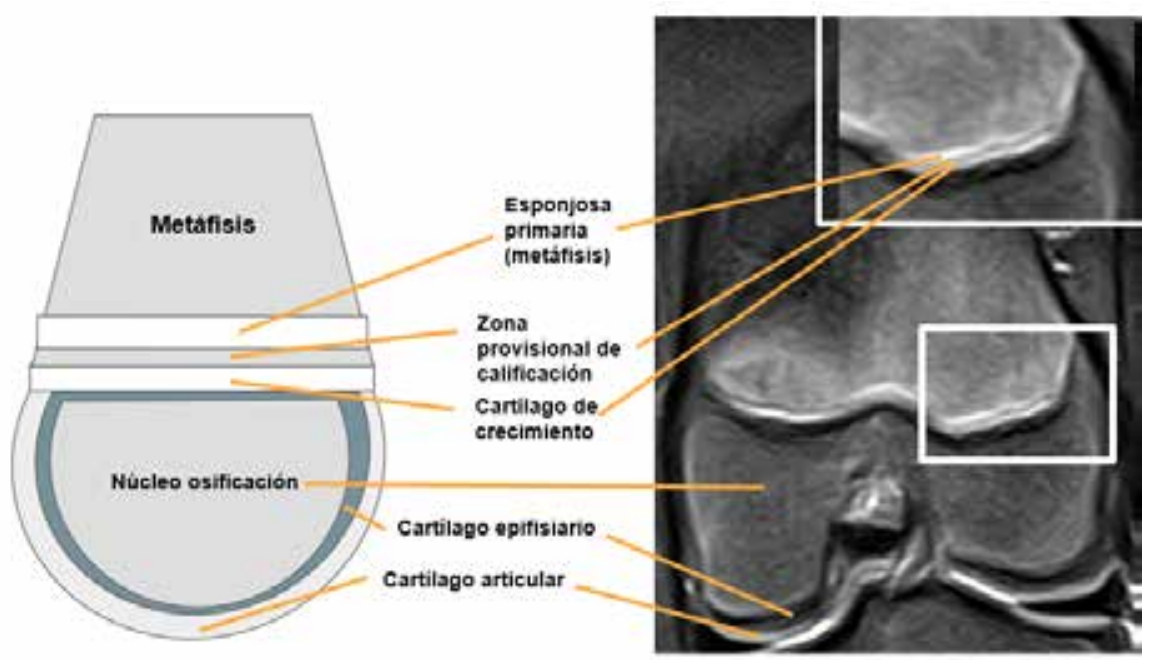

Figura 4. Se observa esquema de distribución capas metáfisis, se compara con las figuras anteriormente descritas. 


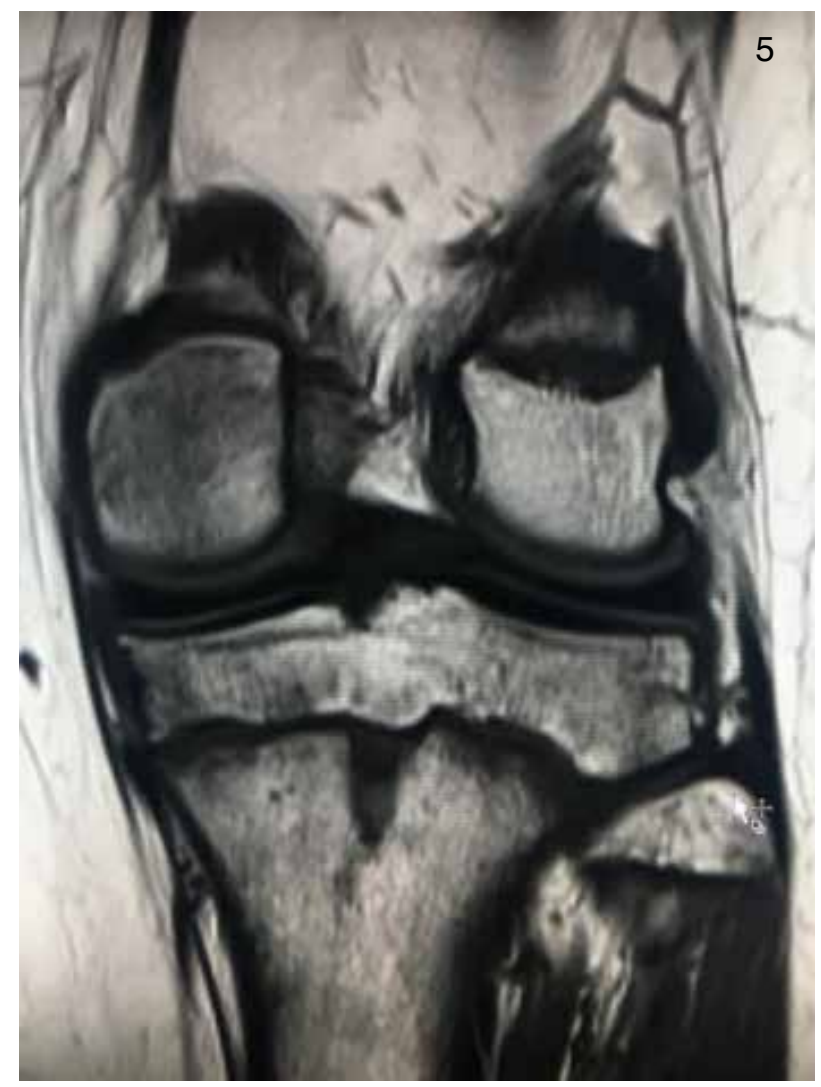

Los pacientes manejados con reposo deportivo e inmovilización presentan, en promedio, mejoría clínica y radiológica en un período de 3 meses, mientras que los que mantienen el nivel de entrenamiento y exigencia evolucionarán a largo plazo con dolor crónico y muchas veces podrán evidenciar complicaciones como barras fisiarias y alteración del crecimiento, tipo dismetrías o angulación patológica de extremidades ${ }^{2}$.
Figura 5. RM T1 coronal de otro paciente que demuestra engrosamiento fisiario y extensión en forma de "lenguetas" de la fisis hacia la metáfisis, característico en injurias de mayor cronicidad.

\section{Conclusión}

La imagenología es fundamental en el diagnóstico precoz de las lesiones por estrés de la placa de crecimiento. El radiólogo debe ser capaz de identificar los cambios radiológicos en estas lesiones y, en los casos que lo requieran, sugerir estudio complementario con RM, para asegurar un diagnóstico precoz y preciso para estos pacientes, que conduzca al adecuado manejo de esta patología e impida complicaciones futuras.

\section{Agradecimientos}

Agradecemos a la Dra. Karla Moënne y Dr. Claudio Berrios la revisión del manuscrito.

\section{Referencias}

1. Jaimes $C$, Jiménez $M$, Shabshin $N$, Laor $T$, Jaramillo D. Taking the stress out of evaluating stress injuries in Children. Radiographics 2012; Mar-Apr; 32(2): 537-555.

2. Laor T, Wall E, Vu L. Physeal widening in the knee due to stress injury in child athletes. American Journal of Roentgenology 2006; 186: 1260-1264.

3. Bateni C, Bindra J, Haus B. MRI sports injuries in children and adolescents: What's different from adults. Curr Radiol rep 2014; $2: 45$.

4. Anderson MW. Imaging of upper extremity stress fractures in the athlete. Clin Sports Med 2006 Jul; 25(3): 489-504, vii.

5. Obeme O, Gaskin C, Taffoni M, Anderson M. Little Leaguer's shoulder: MRI findings in four boys. Pediatr radiol 2007; 37 (9) 885-889.

6. Caine D, DiFiori J, Maffuli N. Physeal injuries in children's and youth sports: reason for concerns? Br J Sports Med. 2006 Sep; 40(9): 749-760. 